\title{
HANS BELLMER \& DAVID NEBREDA: ÓRGÃOS DESTERRITORIALIZADOS
}

\author{
Jonathan Mendes Tavares ${ }^{1}$
}

\section{A técnica anatômica e a produção do corpo organizado}

No momento em que o corpo humano passou a ser enunciado como uma categoria, como objeto de pesquisa pertencente à produção do pensamento ocidental, sobretudo na modernidade, ele também se tornou alvo de uma intensa proliferação discursiva viabilizada e efetuada em função da organização do pensamento em áreas de conhecimento (anatomia, biologia, fisiologia, medicina), e que se dispõem a um incansável exercício por sua definição e unificação no campo da linguagem. Entre os séculos XVI e XVII, com o aparecimento de novas formas de organização e institucionalização do saber por meio das disciplinas (FOUCAULT, 2004) estabelece-se uma disputa por sua significação no campo conceitual. O discurso científico moderno acerca do corpo humano encontra no desenvolvimento da anatomia moderna, assim como nas demais disciplinas constituintes do saber biomédico importante base de sustentação e definição; é o corpo em sua consistência material que interessa ao conjunto das técnicas anatômicas delimitar: teórica e empiricamente, e do mesmo modo, organizá-lo e por ele responder.

Significação recorrente veiculada por disciplinas como a Anatomia, a Fisiologia, a Citologia e a Histologia, organizadoras dos saberes biomédicos é compreender o corpo como realidade exclusivamente biológica. Estudam-se os tipos de células e a composição histológica dos tecidos formadores dos órgãos; estes possuem funções fisiológicas responsáveis pelo funcionamento saudável dos vários sistemas aos quais eles dão origem: endócrino, circulatório, nervoso, cardiovascular, muscular, articular, esquelético, respiratório, digestório, etc. O conjunto desses sistemas compostos por órgãos formarão um organismo, definido como qualquer espécie de ser vivo. Extraímos dessa sentença certa organização permeada por uma lógica hierárquica de acúmulos sucessivos, amontoados celulares que formam estratos, camadas sobre camadas (SPENCE, 1991). Desde uma perspectiva científica esse é um tipo de significação recorrente quando se pensa em como um corpo é organizado; o corpo é definido a partir de sua origem biológica, ancorada por um senso de normalidade, instituindo um padrão de ordem.

Uma definição científica ainda hoje utilizada em congressos internacionais de anatomia refere-se à monstruosidade (SPENCE, 1991); termo utilizado na literatura especializada para definir tudo aquilo que escapa à ordem do organismo, ou seja, para uma unidade celular se tornar um organismo, é necessário percorrer a sentença de acúmulos sucessivos de amontoados celulares numa lógica de soma de estratos, que produza um montante de carne e sangue. Quando essa sequência orgânica do organismo não é cumprida, por exemplo, por uma patologia que inviabiliza o desenvolvimento sadio de algum desses sistemas, causando prejuízo funcional ou incompatibilidade com a vida, temos uma monstruosidade, ao invés de um corpo. $\mathrm{O}$ desenvolvimento do saber anatômico, portanto, não apenas esquadrinha o corpo para organizálo e representá-lo em função desse saber, como modela nossa compreensão sobre sua consistência material via regime visual. $\mathrm{O}$ entendimento e o uso que se faz de sua materialidade certamente é orientado pela circulação desse aprendizado (ORTEGA, 2008).

O conhecimento científico geralmente configura-se como uma máquina enunciadora de regimes de veridicção (FOUCAULT, 2004). Do acúmulo de informações que subsidiam

\footnotetext{
1 Escola de Artes, Ciências e Humanidades (EACH), da Universidade de São Paulo (USP). E-mail: jonathan.tavares@usp.br.
} 
determinadas comprovações, decorrentes da observação de uma realidade objetiva, formas fixas de perceber e conhecer o corpo produzem modelos de normalidade que serão replicados. A assimilação e reprodução desses modelos - e a consequente denúncia das "monstruosidades" - não restringem-se apenas ao ambiente higiênico de laboratórios de anatomia; esta mesma coerência normativa julgadora da organização dos órgãos, a mesma que submeterá o comportamento humano no campo social, interfere na produção dos modos como os indivíduos experimentam e fazem uso de seus corpos no espaço.

Se o corpo e a própria vida são convertidos em objetos prioritários para o desenvolvimento da anatomia, interessa encontrar elementos que, porventura, façam estremecer sua primazia; abordagens capazes de abrir fendas na totalidade de seu discurso, revigorando-o e retirando-o de uma imagem estratificada e organizada sob a condição de que sua própria matéria esteja afastada da vida. Assim, seria necessário despir o corpo de sua organização fisiológica, causando um curto circuito na biunivocidade órgão-função, arrancar o corpo de sua anatomia orgânica, desterritorializar os órgãos e atirá-los numa massa amorfa que já não reconhece utilitarismo pré-existente à ação e que não se adéqua mais, portanto, a qualquer processo de instrumentalização que capture sua potência de produção.

\section{Hans Bellmer \& David Nebreda: órgãos desterritorializados}

Os artistas Hans Bellmer (1902 - 1975) e David Nebreda de Nicolas (1952) produzem, cada um a seu modo, um conjunto de trabalhos estéticos cuja atenção recai sobre o corpo. Não se trata de séries imagéticas, representando um organismo em sua organização fisiológica; o organismo é uma encenação que nunca coincidiu com a vida e, no entanto buscou precisamente na morte, sua condição de representação e captura. Os corpos criados por Hans Bellmer e David Nebreda pervertem a anatomia orgânica para extrair dela, não suas formas, mas as forças capazes de perturbar definições ordinárias que se dedicam a estratificar o corpo exatamente nas formas provisórias por meio das quais ele se apresenta. Tomamos, portanto, as obras desses dois artistas como "evidências" de regimes visuais na arte que se opõem à estratificação do corpo produzida pela imagem anatômica.

O alemão Hans Bellmer ${ }^{2}$ produz um catálogo fotográfico constituído por bonecas no qual realiza um processo de montagem e desmontagem de peças oriundas de corpos de bonecos e bonecas; reelaboradas como anagramas, essas peças possibilitam uma variedade de montagens, conforme as figuras 1,2 e 3.

Para ancorar sua produção Bellmer cria o conceito de inconsciente físico, ou seja, os caminhos que o desejo percorre no corpo, mas que não são visíveis (SOARES, 2016 apud RAVELLI, 2016). Quando as peças dos bonecos são remontadas e, portanto, suas anatomias orgânicas são pervertidas, tem-se o efeito da duração desse desejo - como variação anatômica, ou ainda como anti-anatomia, percorrendo todo o corpo. Nesse sentido

As versões posteriores da boneca acentuam o sistema operatório através do qual Bellmer desenvolve os princípios de uma anatomia metamórfica visionária; isolar uma parte, desmembrar, mutilar, depois desarticular e rearticular diferentemente, combinar ao infinito as montagens corporais possíveis e impossíveis ou mesmo monstruosas" (MATESCO, 2009, p. 39).

\footnotetext{
${ }^{2}$ Obras disponíveis no sítio do Museum of Modern Art (MoMa): <https://www.moma.org/artists/452> Acesso em: 10 Ago. 2017.
} 


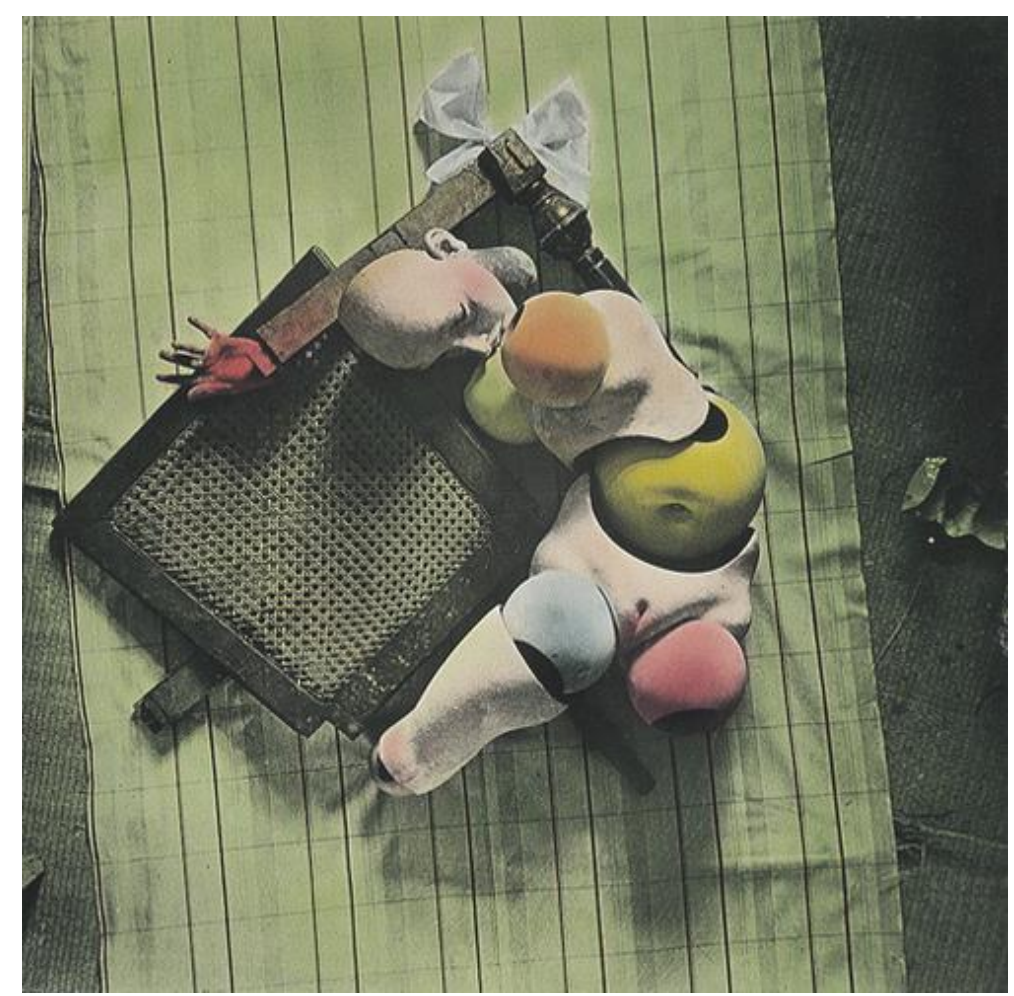

Figura 1 - La poupée, 1935-1949

Fonte: https://br.pinterest.com/pin/436989970085952420

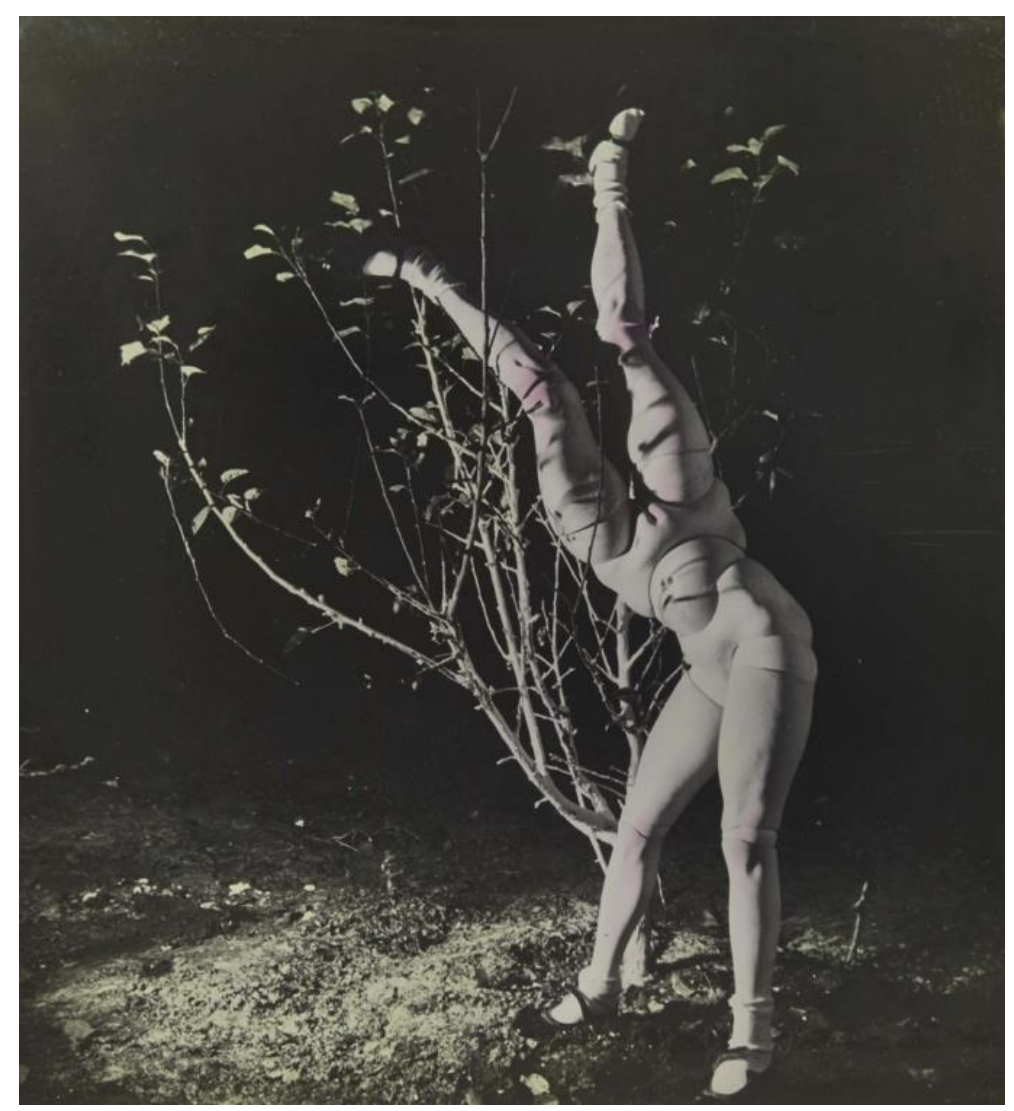

Figura 2 - La poupée (“The dool”), 1935

Fonte: https://www.artslant.com/sp/works/show/898871 


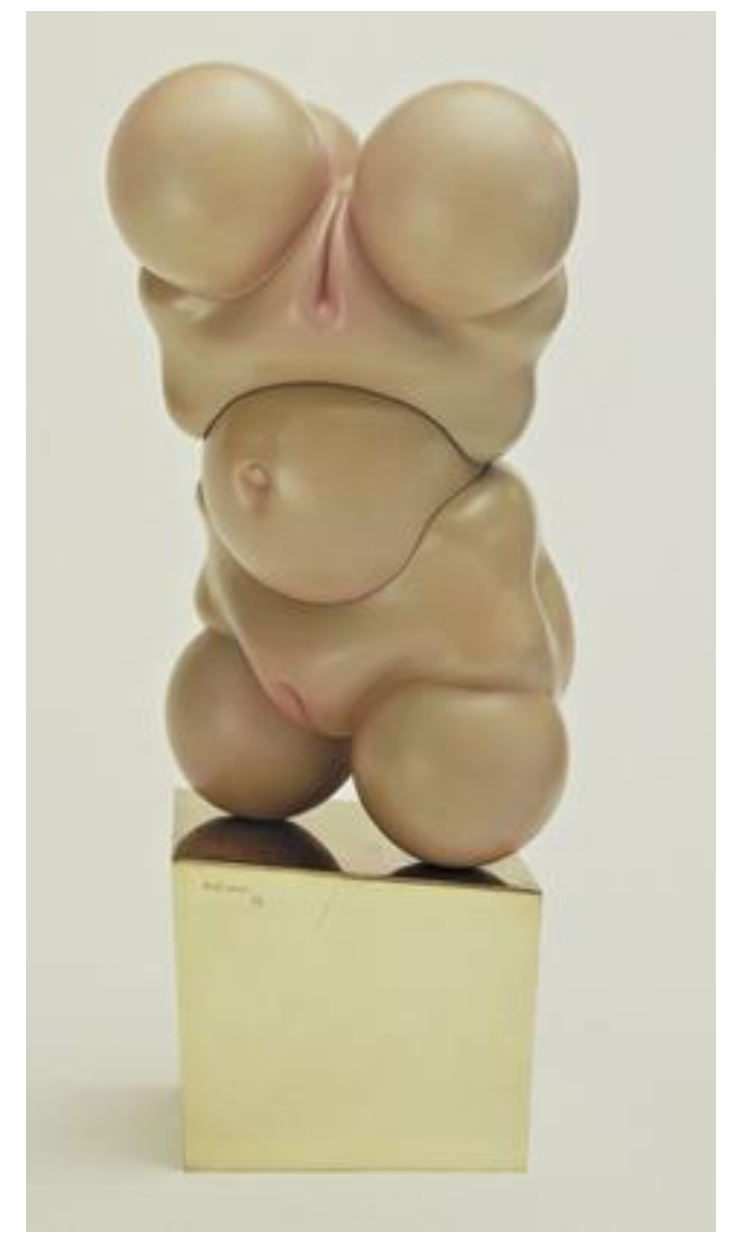

Figura 3: Doll, Paris (1936)

Fonte: http://www.moma.org/collection/works/81611?artist id=452\&locale=pt\&page=1\&sov referrer=artist

Paralelo ao trabalho de Hans Bellmer, mas trilhando um trajeto distinto, o fotógrafo espanhol David Nebreda, diagnosticado com esquizofrenia aos 19 anos, faz de seu próprio corpo um campo de batalha no qual desenvolve uma luta consigo mesmo. A relação performativa mantida por Nebreda com seu corpo estabelece um plano de experimentação efetuado em sua própria carne. Entre os procedimentos físicos adotados ele submete-se a jejuns severos que reelaboram as formas provisórias por meio das quais seu corpo é apresentado. Sua anorexia não coincide com um distúrbio categorizado pelo campo biomédico, mas como um investimento sobre si, rejeitando a determinação disciplinada do organismo.

A anorexia é, talvez, aquilo de que se falou da pior maneira, sob a influência da psicanálise, notadamente: o vazio, próprio ao corpo sem órgãos anoréxico, não tem nada a ver com uma falta, e faz parte da constituição do campo de desejo percorrido de partículas e de fluxos. (DELEUZE; PARNET, 1998, p. 106).

Em Diálogos, Gilles Deleuze e Claire Parnet (1998) reelaboram o processo anoréxico como fenômeno não pertencente ao campo patológico, ao conceberem-no como um exercício prático sobre si, capaz de problematizar a pré-determinação dos padrões fisiológicos:

Não se trata de uma recusa do corpo, trata-se de uma recusa do organismo, de uma recusa do que o organismo faz o corpo sofrer. De modo algum regressão, e sim involução, corpo involuído. O vazio anoréxico não tem nada a ver com 
uma falta, é, ao contrário, uma maneira de escapar à determinação orgânica da falta e da fome, à hora mecânica da refeição. Há todo um plano de composição do anoréxico, para se fazer um corpo anorgânico (o que não quer dizer assenlado: ao contrário, devir-mulher de todo anoréxico). A anorexia é uma política, uma micro-política: escapar às normas do consumo, para não ser objeto de consumo. [...] O anoréxico é um apaixonado: ele vive de várias maneiras a traição ou o duplo desvio. Ele trai a fome, porque a fome o trai, sujeitando-o ao organismo; ele trai a família porque a família o trai sujeitandoo à refeição familiar e a toda uma política da família e do consumo (substituir a isso um consumo interrompido, mas neutralizado, asseptizado); enfim, ele trai o alimento, porque o alimento é traidor por natureza (idéia do anoréxico, que o alimento está cheio de larvas e de venenos, vermes e bactérias, essencialmente impuro, daí a necessidade de escolher e de extrair dele partículas, ou de cuspi-las novamente). Estou morrendo de fome, diz ela, precipitando-se sobre dois "yogurts dietéticos". Engana-a-fome, engana-afamília, engana-o-alimento. Em suma, a anorexia é uma história de política: ser o involuído do organismo, da família ou que uma sociedade de consumo. [...] É verdade que a psiquiatria ou a psicanálise não compreendem, porque elas rebatem tudo sobre um código neuro-orgânico, ou simbólico ("falta, falta...”). Surge, então, outra questão: porque o agenciamento anoréxico corre o risco de descarrilhar, de tornar-se mortífero? Que perigos ele sempre beira, e em quais ele cai? É uma questão que deve ser colocada de maneira diferente de como a psicanálise a coloca: é preciso procurar quais são os perigos que ocorrem no meio de uma experimentação real, e não a falta que preside a uma interpretação preestabelecida. (DELEUZE; PARNET, 1998, p. 127-129).

Para que o agenciamento anoréxico não se converta, entretanto, em uma experiência mortífera, a prudência com esse modo de exercício torna-se, neste caso, uma coerente condição para a experimentação corpórea. Doses de prudência convertem-se em um amparo para o que o próprio excesso e a radicalidade da experimentação não destrua o experimento: "Desfazer o organismo nunca foi matar-se, mas abrir o corpo a conexões que supõe todo um agenciamento, circuitos, conjunções, superposições, limiares, passagens." (DELEUZE; GUATTARI, 2004, p. 21). David Nebreda, portanto, empreende, através da relação material com seu próprio corpo e o agenciamento anoréxico, um plano de composição decorrente da criação de uma estética que recusa o organismo, para fazer do corpo um campo de variação no qual as formas anatômicas se modificam em função de cada experimentação. 


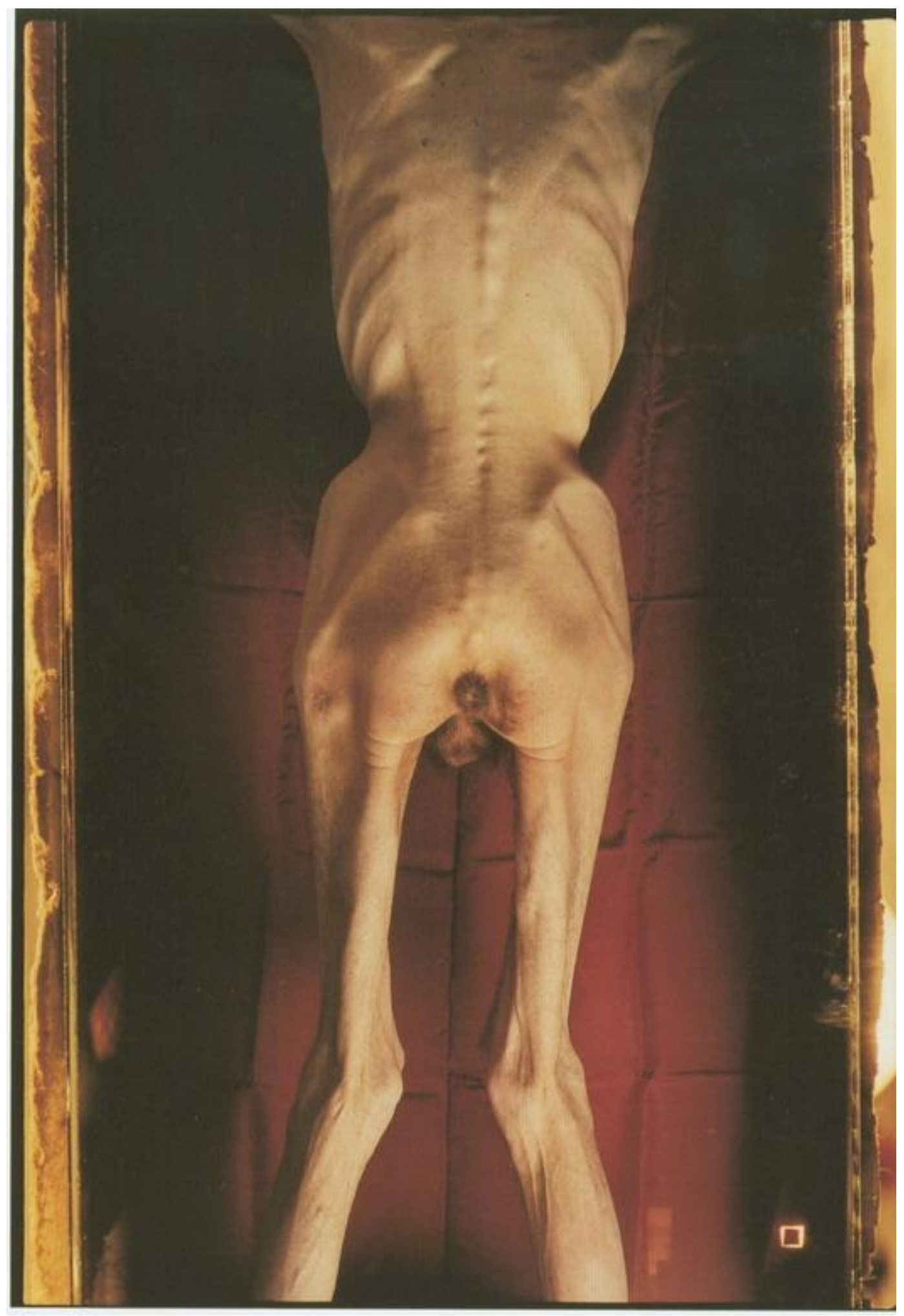

Figura 5. Fotografia de David Nebreda

Fonte: https://lasociedadsupersecreta.files.wordpress.com/2014/02/david-nebreda7.jpg 


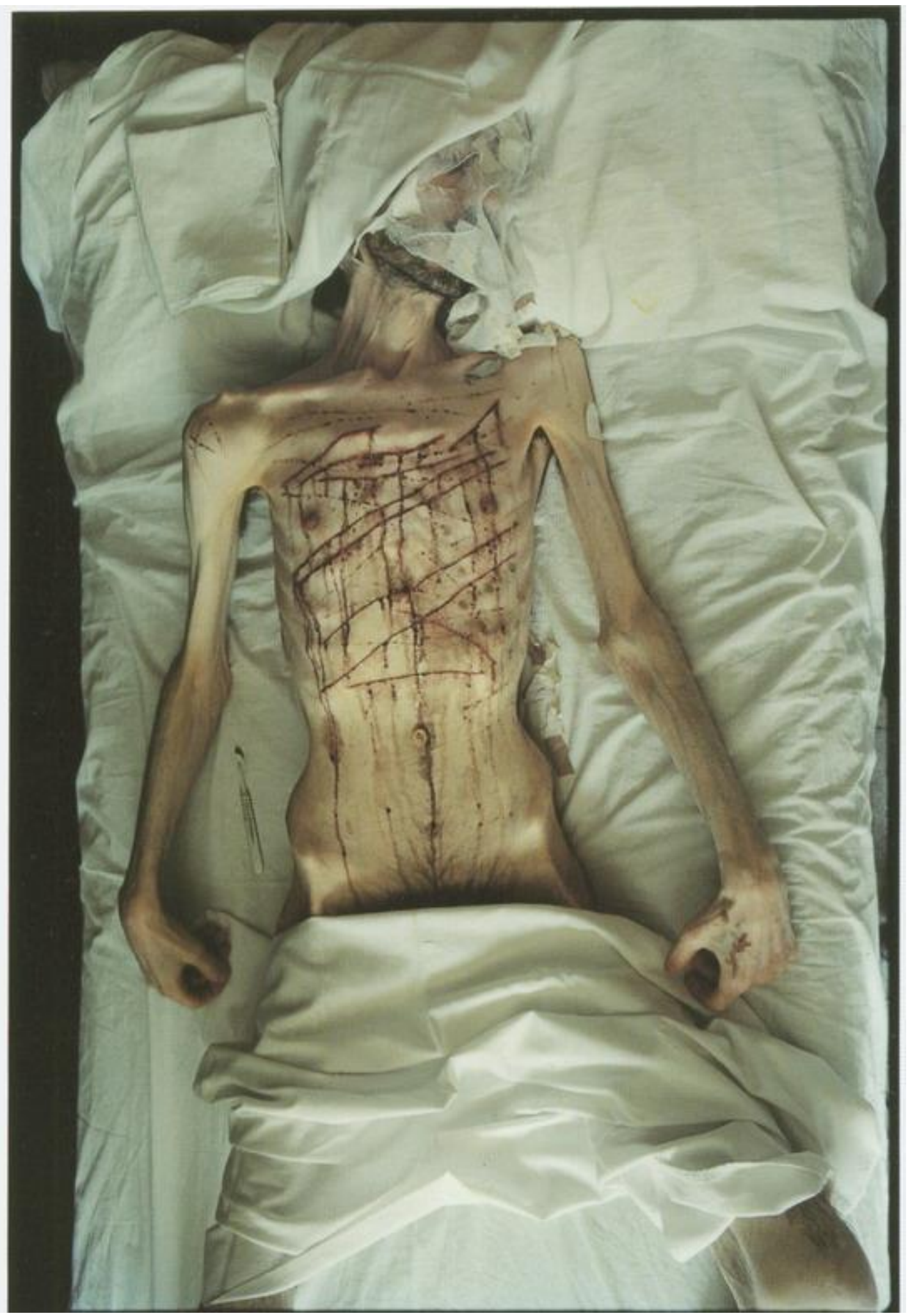

Figura 5. Fotografia de David Nebreda

Fonte: https://ic.pics.livejournal.com/dalaruan/13984359/34417/34417_original.jpg

Os trabalhos de Hans Bellmer e David Nebreda são possibilidades de evidenciar como a rostificação exercida pela anatomia sobre o corpo pode ser desfeita por agenciamentos, responsáveis por impelir esse mesmo corpo entrar em variação contínua ao ponto de fazê-lo perder 
o organismo, entretanto, a mobilização desses exemplos não tem como objetivo esgotar a discussão via comparação entre as formas. Assim, não basta somente constatar como as formas do corpo de David Nebreda ou as formas de corpo criadas por Hans Bellmer não coincidem com as formas do corpo dissecado nos atlas anatômicos, mas perceber que a eficácia do trabalho de Nebreda reside na força dos agenciamentos de seu corpo, produzindo variações sustentadas por ele.

A mobilização de evidências a partir dos trabalhos dos dois artistas que fazem colidir o imaginário anatômico, será eficaz se considerada como discussão das forças composicionais atuantes sobre esses corpos, dando a ver suas formas; processo este diferente da estratificação anatômica ancorada no decalque de formas sedentarizadas, possíveis se efetuarem por meio da matéria morta. Por que as formas de corpo produzidas sob um regime artístico não coincidem com as formas de corpo do regime anatômico? No caso de Nebreda, porque é a partir da vida que um corpo pode comportar um plano de composição, permitindo-lhe produzir variações e fazer surgir as formas; e, no caso de Bellmer, a ausência de um plano de composição via interdição da morte, faz com que reste tão só à anatomia extrair do cadáver as formas a serem decalcadas: “o corpo sem órgãos não é um corpo morto, mas um corpo vivo, e tão vivo e tão fervilhante que ele expulsou o organismo e sua organização" (DELEUZE; GUATTARI, 2009, p. 43).

É importante insistir nesse ponto, pois pouco adiantaria trazer esses exemplos do campo da arte para simplesmente opor suas formas àquelas postas em jogo pela anatomia. As formas apresentadas por esses corpos, vinculados ao regime da arte, somente podem surgir mediante um plano de composição, com seus agenciamentos inesperados e suas formas, dando a ver imediatamente seu plano de composição: "Há todo um plano de composição do anoréxico, para se fazer um corpo anorgânico" (DELEUZE; PARNET, 1998, p. 128), ao passo que as formas apresentadas pelos corpos da anatomia apenas podem surgir da ausência da vida, da ausência de um plano de composição, restando-lhe extrair as formas de uma matéria morta para constituir o organismo.

O organismo seria então a estratificação, a coagulação de formas cujo aparecimento é viabilizado por um estado de morte: "buscar a vida na dissecação é perdê-la no momento da ação" (POPE apud LEWONTIN, 2002, p. 76), mas o plano de composição é a condição de todo o corpo vivo para intervir sobre si, inventando outros modos de vida não coincidentes com o organismo. Esses planos de composição podem se efetuar, como nos casos de Hans Bellmer e David Nebreda, via um regime artístico desde o qual se agenciam fetiche e libido ou anorexia e celibato, mas não se esgotam na arte.

\section{Referências}

DELEUZE, G.; GUATTARI, F. Mil Platôs: capitalismo e esquizofrenia. v. 1. Tradução de Aurélio Guerra Neto e Celia Pinto Costa. São Paulo: Editora 34, 2009.

DELEUZE, G.; GUATTARI, F. Mil Platôs: capitalismo e esquizofrenia. v. 3. Tradução de Aurélio Guerra Neto, Ana Lúcia de Oliveira, Lúcia Claudi Leão e Suely Rolnik. São Paulo: Editora 34, 2004.

FOUCAULT, M. A ordem do discurso. 11. ed. São Paulo: Loyola, 2004.

LEWONTIN, R. C. A Tripla Hélice: Gene, Organismo, Ambiente. Tradução de José Viegas São Paulo: Companhia das Letras, 2002.

MATESCO, V. Corpo, Imagem e Representação. Rio de Janeiro: Zahar, 2009. 
ORTEGA, F. O corpo incerto: corporeidades, tecnologias médicas e cultura contemporânea. Rio de Janeiro: Garamond, 2008.

RAVELLI, J. Ocupação em SP celebra 20 anos de carreira de Marta Soares. $O$ Estado de $S$. Paulo, São Paulo, 02 mar. 2016. Disponível em: <http://cultura.estadao.com.br/noticias/teatroe-danca,ocupacao-em-sp-celebra-20-anos-de-carreira-de-marta-soares,10000019051>. Acesso em: 20 jan. 2018.

SPENCE, A. P. Anatomia Humana Básica. São Paulo: Editora Manole, 1991. 